\title{
Prevalence of inherited ichthyosis in France: a study using capture-recapture method
}

\author{
Isabelle Dreyfus ${ }^{1 *}$, Cécile Chouquet ${ }^{2}$, Khaled Ezzedine ${ }^{3}$, Sophie Henner ${ }^{1}$, Christine Chiavérini ${ }^{4}$, Aude Maza', \\ Sandrine Pascal ${ }^{2}$, Lauriane Rodriguez ${ }^{1}$, Pierre Vabres ${ }^{5}$, Ludovic Martin $^{6}$, Stéphanie Mallet ${ }^{7}$, Sébastien Barbarot $^{8}$, \\ Jérôme Dupuis ${ }^{2}$ and Juliette Mazereeuw-Hautier ${ }^{1}$
}

\begin{abstract}
Background: Inherited ichthyoses represent a group of rare skin disorders characterized by scaling, hyperkeratosis and inconstant erythema, involving most of the tegument. Epidemiology remains poorly described. This study aims to evaluate the prevalence of inherited ichthyosis (excluding very mild forms) and its different clinical forms in France.

Methods: Capture - recapture method was used for this study. According to statistical requirements, 3 different lists (reference/competence centres, French association of patients with ichthyosis and internet network) were used to record such patients. The study was conducted in 5 areas during a closed period.

Results: The prevalence was estimated at 13.3 per million people (/M) (C195\%, [10.9 - 17.6]). With regard to autosomal recessive congenital ichthyosis, the prevalence was estimated at 7/M (Cl 95\% [5.7 - 9.2]), with a prevalence of lamellar ichthyosis and congenital ichthyosiform erythroderma of 4.5/M (Cl 95\% [3.7 - 5.9]) and 1.9/M (Cl 95\% [1.6 - 2.6]), respectively. Prevalence of keratinopathic forms was estimated at 1.1/M (CI 95\% [0.9 - 1.5]). Prevalence of syndromic forms (all clinical forms together) was estimated at 1.9/M (Cl 95\% [1.6 - 2.6]).
\end{abstract}

Conclusions: Our results constitute a crucial basis to properly size the necessary health measures that are required to improve patient care and design further clinical studies.

Keywords: Inherited ichthyosis, Epidemiology, Prevalence, Capture-recapture method, Genodermatosis

\section{Background}

Inherited ichthyoses represent a large group of monogenic Mendelian disorders of cornification due to mutations in genes involved in skin barrier function [1]. Skin changes, affecting all or most of the tegument, are characterized by scaling, hyperkeratosis or both. Erythema is inconstantly present. According to a recent ichthyosis expert consensus, the classification should be clinically based and distinguish between syndromic and nonsyndromic ichthyoses [2].

Except for very mild forms of ichthyosis, the disease was demonstrated to have a significant impact on quality of life (QOL) [3-7]. During the past few years, much progress has been achieved in describing the molecular basis of these disorders and in establishing genotype-phenotype

\footnotetext{
*Correspondence: dreyfus.i@chu-toulouse.fr

${ }^{1}$ Reference Centre for Rare Skin Diseases, Dermatology Department, Larrey Hospital, CHU Toulouse, Toulouse, France

Full list of author information is available at the end of the article
}

correlations [8]. However, prevalence remains poorly described [9-16] and no patient registration exists. Understanding epidemiology of rare skin disorders such as ichthyosis is one of the main objectives advocated in the Plan Maladies Rares defined by the French Health ministry [17].

The objective of our study was to estimate the prevalence of inherited ichthyoses having a significant impact on QOL (excluding accordingly very mild forms) and to determine the prevalence of their different clinical forms. Patients suffering from such inherited ichthyoses are primarily diagnosed by private or hospital physicians and subsequently usually followed in hospital. Nevertheless, a "hospital list" may not be exhaustive to enumerate such patients, since some of them, who could have been demotivated by the lack of effective treatment for example, might have interrupted their medical care and thus are "out of the hospital healthcare system". It is therefore necessary to identify these patients via additional 
lists of recruitment, hence the choice of capture-recapture method [18-24].

Capture-recapture models are commonly used for estimating prevalence in epidemiological studies when information comes from incomplete lists $[18,19]$. Estimation is based on the number of cases recorded on each list, as well as the overlapping of cases between the lists. This thereby allows for estimation of the number of cases of the target population appearing on no list. The standard statistical approach uses log-linear models. They allow for dealing with possible dependencies between lists, but also include, in particular, the independent model which assumes independence between lists [20,21]. The implementation of such an approach requires at least 3 sources of data.

\section{Methods}

The study protocol was reviewed and approved both by an independent health ethics committee in Toulouse, France and by the CNIL, the French National authority for registers.

The target population consisted of patients suffering from inherited ichthyosis with a confirmed diagnosis performed by a physician at a given time of their illness. We excluded very mild forms that can be defined as ichthyoses with a very mild clinical severity (visual analogue scales (VAS) for erythema and scaling $<1.5 / 10$, in the absence of systemic therapy by acitretin). In practice, these very mild forms correspond to ichthyosis vulgaris or ichthyoses with similar severity.

According to statistical requirements, 3 lists of patients were selected: patients registered in reference/competence centres that are experts for rare skin diseases (L1), members of the French association of patients with ichthyosis (named AIF) (L2) and members of the Facebook social network: "Lichtyose qu'est-ce que c'est?" (L3). The study was conducted in 5 French areas (Aquitaine, Bourgogne, Midi-Pyrénées, Pays de la Loire, Provence Alpes Côte d'Azur (PACA)) during a closed period of 6 weeks (from June $1^{\text {st }} 2011$ to July $15^{\text {th }}$ 2011). Patients were contacted either by phone (L1, L2) or by email (L3) to obtain their consent. Overlaps between lists were identified by checking the first 3 letters of the surname, the first 2 letters of the first name and the date of birth. In order to confirm the population prerequisite closed in time and space, all patients were also asked about their zip code and whether they resided in the selected area for a minimum of 6 weeks (without migratory movements).

For the patients recruited via L1, the diagnosis of the clinical form of ichthyosis and the severity were determined by the clinician in charge. The patients recorded via L2 or L3 (without overlapping with L1) were asked to fill-in a questionnaire exploring ichthyosis characteristics (including VAS for erythema and scaling), which was then reviewed by a board of ichthyosis experts to define the clinical form and the severity (data not shown).

The number of patients suffering from ichthyosis was estimated by considering a set of log-linear models, taking into account possible interactions between lists. In addition to area, individual covariates - such as gender, age (older than 15 years or younger) and grade of severity (mild/moderate/severe/very severe) - were introduced in the model in order to improve the prevalence estimation [25]. A selection model procedure was implemented using the GENMOD procedure of SAS: the best model being the one with the maximum weighted Akaike Information Criterion (wAIC) [26]. The selected model allowed for estimation of the number of ichthyosis patients at several levels: estimation for each area and for the pooled areas, as well as estimation by age group and by severity. Estimated prevalence was finally deduced from the estimated number of ichthyosis patients and the French 2008 census: for each area (regional prevalence) and for the pooled areas (global prevalence), which can be considered as national prevalence, subject to representativeness of the selected areas.

With regard to clinical form, a separate ad hoc statistical procedure was implemented (clinical form cannot be introduced as covariate in the log-linear model because of a very low number of detected patients for some clinical forms). The prevalence of each clinical form was estimated by applying the distribution of clinical forms observed among the reported cases to the estimated global prevalence. This ad hoc procedure is based on the assumption that the capture probability depends on the clinical form mainly through the severity grade, which seems reasonable from a dermatological point of view.

\section{Results}

Three-source observed data

A total of 119 patients suffering from ichthyosis were identified. The observed frequencies according to presence or absence on each list for each area are presented in Table 1. Data was unbalanced: the majority of patients were identified via L1, whereas very few patients were recorded via L3. Overlaps were rather rare and mostly observed between L1 and L2. No patient was captured simultaneously in the 3 lists. Furthermore, some geographic disparities were observed concerning the recruitment of the patients.

\section{Estimation of the number of patients Global estimation (pooled-areas level)}

Among all log-linear models considered (Table 2), the independent sources model with 3 covariates effects was selected: it assumes that the 3 sources are independent, and that the capture probabilities depend on each source and on the 3 individual covariates (area, age and severity 
Table 1 Numbers of patients reported in the three lists, in each of the 5 selected areas

\begin{tabular}{lllllllll}
\hline Area & $\mathbf{1 0 0}^{\mathbf{a}}$ & $\mathbf{0 1 0}$ & $\mathbf{0 0 1}$ & $\mathbf{1 1 0}$ & $\mathbf{0 1 1}$ & $\mathbf{1 0 1}$ & $\mathbf{1 1 1}$ & Total \\
\hline Aquitaine & 5 & 5 & 1 & 3 & 0 & 0 & 0 & 14 \\
Pays de Loire & 10 & 3 & 2 & 5 & 0 & 0 & 0 & 20 \\
Midi-Pyrénées & 44 & 1 & 0 & $8^{\mathrm{c}}$ & 0 & 1 & 0 & $54^{\mathrm{b}}$ \\
PACA & 22 & 3 & 0 & 2 & 1 & 0 & 0 & 28 \\
Bourgogne & 2 & 1 & 0 & 0 & 0 & 0 & 0 & 3 \\
Pooled areas & 83 & 13 & 3 & 18 & 1 & 1 & 0 & 119
\end{tabular}

Legend:

3 digits: First position: list 1 (hospital department); Second position: list 2 (AIF); Third position: list 3 (Facebook network).

Presence in the list: notified as 1 ; absence in the list: notified as 0 .

Examples:

alchthyoses cases reported in list 1 but not reported in lists 2 and 3 .

${ }^{b}$ In Midi Pyrénées area, 54 cases were reported in at least one of the 3 lists.

${ }^{c}$ Among these 54 patients, 8 patients were recorded in list 1 and in list 2 but not in list 3.

grade). Estimation was based on data collected from 4 areas (Aquitaine, Midi-Pyrénées, PACA and Pays de Loire), Bourgogne area being excluded because of non-valid estimations due to very low counts. This model gave a global estimation of 191 patients (95\% CI [157-253]) for the 4 selected areas.

\section{Estimation according to individual covariates}

From this model, we also estimated the number of ichthyosis patients by age group (Table 3): 58 patients under 15 years old (95\% CI [47-79]) and 133 patients aged 15 and older (95\% CI [102-197]), deducing that 70\% of estimated cases were 15 years and older. For each age group,

Table 2 Estimations of number of cases from log-linear models including covariates (based on data of four areas, Bourgogne data excluded)

\begin{tabular}{llll}
\hline & Weighted AIC* & $\begin{array}{l}\text { Estimated } \\
\text { numbers } \\
\text { of cases }\end{array}$ & 95\% Cl \\
\hline Independent sources model & $<.001$ & 184 & {$[150-251]$} \\
$\begin{array}{l}\text { Independent sources model } \\
\text { with age effect }\end{array}$ & $<.001$ & 181 & {$[148-247]$} \\
$\begin{array}{l}\text { Independent sources model } \\
\text { with area effect }\end{array}$ & $<.001$ & 174 & {$[139-260]$} \\
$\begin{array}{l}\text { Independent sources model } \\
\text { with severity effect }\end{array}$ & $<.001$ & 208 & {$[157-324]$} \\
$\begin{array}{l}\text { Independent sources model } \\
\text { with age and area effects }\end{array}$ & $<.001$ & 171 & {$[141-237]$} \\
$\begin{array}{l}\text { Independent sources model } \\
\text { with age and severity effects }\end{array}$ & $<.001$ & 204 & {$[158-299]$} \\
$\begin{array}{l}\text { Independent sources model } \\
\text { with area and severity effects }\end{array}$ & 0.047 & 194 & {$[154-274]$} \\
$\begin{array}{l}\text { Independent sources model } \\
\text { with three covariates effects }\end{array}$ & 0.951 & 191 & {$[157-253]$} \\
\hline
\end{tabular}

*Weighted AIC: weighted Akaike Information Criteria representing the weight of evidence in favor of a particular model among a set of several models.
Table 3 Estimated numbers of patients and estimated capture probabilities by individual covariates

\begin{tabular}{|c|c|c|c|c|}
\hline $\begin{array}{l}\text { Individual } \\
\text { covariate }\end{array}$ & $\begin{array}{l}\text { Numbers } \\
\text { of recorded } \\
\text { patients }\end{array}$ & $\begin{array}{l}\text { Estimated } \\
\text { number of } \\
\text { patients }\end{array}$ & $95 \% \mathrm{Cl}$ & $\begin{array}{l}\text { Estimated } \\
\text { capture } \\
\text { probability }\end{array}$ \\
\hline \multicolumn{5}{|l|}{ Age } \\
\hline Under 15 years & 42 & 58 & [49-79] & $72 \%$ \\
\hline Older than 15 years & 74 & 133 & [102-197] & $56 \%$ \\
\hline \multicolumn{5}{|l|}{ Severity grade } \\
\hline Grade 1 (mild) & 40 & 79 & {$[55-141]$} & $50 \%$ \\
\hline Grade 2 (moderate) & 40 & 67 & [51-107] & $59 \%$ \\
\hline Grade 3 (severe) & 26 & 34 & {$[28-49]$} & $77 \%$ \\
\hline Grade 4 (very severe) & 10 & 11 & [10-17] & $95 \%$ \\
\hline
\end{tabular}

"Estimation obtained from the best log-linear model (independent sources model with three covariates effects).

the associated probability of appearing in at least one list was estimated by the ratio recorded/estimated number of patients: 0.72 for patients under 15 years old and 0.56 for patients aged 15 and older. Similarly, we obtained estimations according to the grade of severity. There were more estimated cases with mild disease than with severe disease: 79 (95\% CI [55-141]) vs. 11 (95\% CI [10-17]). The probability of appearing in at least one list increased with disease severity: it was estimated that $95 \%$ of very severe patients (grade 4) were detected in the study $v$ s. only half of mild patients (grade1).

\section{Estimation for each area}

The estimated number of ichthyosis patients for each area is presented in Table 4. Bourgogne data were excluded from analysis but can be included in models without covariate. When comparing estimates from these models on 4 or 5 areas, we deduced that the estimated number of patients in Bourgogne was around 9 (no confidence interval available with this ad hoc approach).

\section{Estimated prevalence of ichthyosis}

The estimated regional prevalence of ichthyosis (95\% CI) is presented in Table 4. Estimated prevalence differed by area. The global prevalence of ichthyosis based upon data of the 4-pooled areas was estimated at 13.3 per million people (/M) (95\% CI, [10.9-17.6]), which can be considered as national prevalence. When considering prevalence by age group, the prevalence of patients under 15 years old and patients aged 15 and older were estimated at $23 / \mathrm{M}(95 \% \mathrm{CI}[19-31])$ and $11 / \mathrm{M}$ (95\% CI [9-17]), respectively.

\section{Estimated prevalence of the different clinical forms of ichthyosis}

The diagnosis of the clinical form of ichthyosis was performed by the clinician in charge for $85.7 \%$ (102/119) of 
Table 4 Estimated number of patients and estimated prevalence by area

\begin{tabular}{|c|c|c|c|c|c|c|}
\hline Area & $\begin{array}{l}\text { Numbers of } \\
\text { recorded patients }\end{array}$ & $\begin{array}{l}\text { Estimated number } \\
\text { of patients }{ }^{b}\end{array}$ & $95 \% \mathrm{Cl}$ & $\begin{array}{l}\text { Population (number } \\
\text { of residents) }^{c}\end{array}$ & $\begin{array}{l}\text { Estimated } \\
\text { prevalence }^{d}\end{array}$ & $95 \% \mathrm{Cl}$ \\
\hline Aquitaine & 14 & 30 & [19-58] & 3177625 & 9.4 & [6.0-18.3] \\
\hline Pays de Loire & 20 & 35 & {$[26-60]$} & 3510170 & 10.0 & [7.4-17.1] \\
\hline Midi-Pyrénées & 54 & 60 & {$[56-77]$} & 2838228 & 21.1 & [19.7-27.1] \\
\hline PACA & 28 & 66 & [41-134] & 4882913 & 13.5 & [8.4-27.4] \\
\hline 4 pooled areas ${ }^{a}$ & 116 & 191 & [157-253] & 14408936 & 13.3 & [10.9-17.6] \\
\hline
\end{tabular}

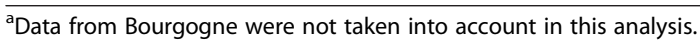

${ }^{b}$ Estimation obtained from the best log-linear model (independent sources model with three covariates effects).

'Provided by the French 2008 census.

${ }^{\mathrm{d}}$ Per million people.

patients. For the remaining 17 patients (registered in L2 and L3, without overlapping with L1), inclusion criteria were encountered (no patient without ichthyosis, no very mild forms) and the clinical form was unequivocally determined by the expert board. Estimated prevalence for each clinical form is presented in Table 5 .

More than $85 \%$ of the patients had a non-syndromic form of ichthyosis, with two-thirds diagnosed as Autosomal Recessive Congenital Ichthyosis (ARCI). Prevalence of ARCI was estimated at 7/M (95\% CI [5.7-9.2]) with a ratio Lamellar Ichthyosis (LI)/Congenital Ichthyosiform Erythroderma (CIE) of 2.4. When considering prevalence of ARCI by age group, the prevalence of patients under 15 years old and aged 15 and older were estimated at 12.1/M (95\% CI [10.2 - 16.5] and 5.9/M (95\% CI [4.5 - 8.7]), respectively. Prevalence of recessive X-linked Ichthyosis (XLI) was estimated to $2.4 / \mathrm{M}$, i.e. 4.9 cases per million males (CI 95\% [4.1 - 6.6]), according to a ratio

Table 5 Estimated prevalence of the different clinical forms of ichthyosis

\begin{tabular}{|c|c|c|}
\hline Clinical forms of ichthyosis & $\begin{array}{l}\text { Number of recorded patients } \\
\text { (percentage)* }\end{array}$ & $\begin{array}{l}\text { Estimated prevalence per million people } \\
\text { ( } 95 \% \text { confidence interval) }\end{array}$ \\
\hline All clinical forms & 116 & $13.3[10.9-17.6]$ \\
\hline Non syndromic ichthyoses (ichthyosis vulgaris excluded) & $99(85.3)$ & $11.3[9.3-15.0]$ \\
\hline $\mathrm{ARCl}$ & $61(52.6)$ & $7.0[5.7-9.2]$ \\
\hline \multicolumn{3}{|l|}{ Major variants: } \\
\hline Lamellar ichthyosis & 39 (33.6) & $4.5[3.7-5.9]$ \\
\hline Congenital ichthyosiform erythroderma & $17(14.7)$ & $1.9[1.6-2.6]$ \\
\hline \multicolumn{3}{|l|}{ Minor variants: } \\
\hline Bathing suit ichthyosis & $4(3.4)$ & $0.46[0.38-0.61]$ \\
\hline Self healing collodion baby & $1(0.9)$ & $0.11[0.09-0.15]$ \\
\hline X-linked ichthyosis & $21(18.1)$ & $2.4[2.0-3.2]$ \\
\hline Keratinopathic ichthyosis & $10(8.6)$ & $1.1[0.9-1.5]$ \\
\hline Other forms & $7(6.0)$ & $0.80[0.66-1.06]$ \\
\hline Erythrokeratodermia variabilis & $4(3.4)$ & $0.46[0.38-0.61]$ \\
\hline Peeling Skin Disease & $1(0.9)$ & $0.11[0.09-0.15]$ \\
\hline KLICK syndrome & $2(1.7)$ & $0.23[0.19-0.30]$ \\
\hline Syndromic ichthyoses & $17(14.7)$ & $1.9[1.6-2.6]$ \\
\hline Syndromic X-linked ichthyosis & $1(0.9)$ & $0.11[0.09-0.15]$ \\
\hline Conradi - Hünermann - Happle syndrome & $2(1.7)$ & $0.23[0.19-0.30]$ \\
\hline Netherton syndrome & $7(6.0)$ & $0.80[0.66-1.06]$ \\
\hline Trichothiodystrophy & $2(1.7)$ & $0.23[0.19-0.30]$ \\
\hline Sjögren - Larsson syndrome & $1(0.9)$ & $0.11[0.09-0.15]$ \\
\hline KID syndrome & $3(2.6)$ & $0.34[0.28-0.45]$ \\
\hline Neutral lipid storage disease & $1(0.9)$ & $0.11[0.09-0.15]$ \\
\hline
\end{tabular}

*Bourgogne area excluded (3 patients). 
female/male: $51.4 \% / 48.6 \%$, provided by the French 2008 census). Prevalence of keratinopathic forms was even lower: 1.1/M (95\% CI [0.9-1.5]).

Less than $15 \%$ of patients had syndromic ichthyosis with an estimated prevalence of 1.9/M (95\% CI [1.6-2.6]). Netherton syndrome was the most frequent form, with 0.80/M (95\% CI [0.66-1.06]).

\section{Discussion}

This is the first study investigating prevalence of inherited ichthyosis (excluding very mild forms) in France. This prevalence was estimated at 13.3/M (95\% CI, [10.9-17.6]), with more than half of the patients suffering from ARCI.

Capture-recapture method was appropriate for estimating prevalence of rare diseases. Indeed, cross-sectional studies are the main alternative to estimate prevalence but may fail in case of rare disease because, even in large samples, it is possible to detect no case [27]. Requirements of the capture-recapture method were respected [18]. The target population was closed (no entry or loss of patients during the study period); individuals have been correctly recorded; there was no matching error; any individual of the target population had a strictly positive probability to appear on any list.

The choice of our 3 lists was based on the followings points: patients are often seen even once in expert centres for rare skin disease (L1). The association AIF (L2) is the only patient support group in France and registers a significant number of patients (approximately 250 members). The choice of a social network (L3) was based on patients' enthusiasm for searching information or communicating via internet (more than 100 members). Recruitment via L2 and L3 (17 non-hospital patients: 14.3\%) was not negligible which confirmed the appropriateness of the capture-recapture method and the choice of the lists. The choice of the 5 areas was based on the presence of a reference/competence centre. These areas can be considered as representative of France since they are scattered throughout the country and cover more than $20 \%$ of the population.

From a statistical point of view, sparse and unbalanced data induced some difficulties. Indeed it was not possible to include the clinical form in our selection model procedure because the statistical procedure implemented by SAS did not provide valid estimates due to computational difficulties. These statistical difficulties were solved by implementing ad hoc approaches. Other statistical approaches which require some specific theoretical developments are possible and could be proposed in future studies. To complete our statistical analysis, the pseudo- $\mathrm{R}^{2}$ proposed by Mc Fadden [28] was calculated: $74 \%$ of data variability was explained by the selected model, highlighting its good fitness and its explanatory power.
One limitation of the study could be the use of a selfassessment severity scoring by patients from L2 and L3 who could not be seen by the clinicians involved in the study. Nevertheless, all diagnoses were unequivocally determined by the expert board. In addition, our study did not provide an estimation of the prevalence of the entire ichthyosis population. This could be achieved in the future by the creation of well-designed register involving also private physicians.

In the literature, only a few studies have specifically focused on ichthyosis's prevalence. Earliest studies were conducted outside Europe (Saudi Arabia and Tunisia) and concluded to prevalence which seems different than European one because of a high level of consanguinity [9-12]. In Europe, two recent Spanish studies have dealt with ichthyosis prevalence $[13,14]$. Contrary to our study, only ARCI were concerned. The first one found a prevalence of ARCI consistent with ours, although slightly higher $(8.2 / \mathrm{M})$ but the method used for estimation was not clearly described [13]. The second one was an epidemiological study (144 patients) that used the same capture-recapture method [14]. ARCI's prevalence was almost identical to ours, with a similar proportion of LI/CIE/minor variants: 7.2/M (CI 95\% [5.7 - 9.7]; $62.5 / 30.6 / 7 \%)$ for the Spanish estimation vs. $7 / \mathrm{M}$ (CI 95\% [5.7 - 9.2]; 64/28/8\%) for our study. In addition, estimates of ARCI's prevalence in the Spanish population depended on the age group (the younger the age group, the higher the prevalence) with an ARCI's prevalence of 16.2/M (CI 95\% [13.3 - 23.0]) for the patients younger than 10 years. This age effect was also found in our estimates (23/M (95\% CI [19-31]) for patients younger than 15 years old $(12.1 / \mathrm{M}(95 \%$ CI $[10.2-16.5])$ when only considering ARCI). In the United States, incidence of ichthyosis during the first year of life (excluding common forms which are not diagnosed at birth) was estimated to 6.7 per 100.000 from large administrative claims databases [15].

With regards to keratinopathic ichthyosis, a recent Japan survey had estimated the number of patients to 55 (CI 95\% [35 - 75]) which corresponds to a lower prevalence $(0.44 / \mathrm{M}$ (CI 95\% [0.28 - 0.59])) than ours. Nevertheless, Japanese patients seen only in Dermatology departments were concerned [16]. With regard to XLI, some studies had concluded to a substantial prevalence, possibly excessive, that ranges from 1 case per 10000 to 1 case per 2000 males (large ratio of 5:1), depending on the study population and the method of assessment [29-32]. Our XLI prevalence was lower. It is therefore difficult to conclude formally about the real prevalence of XLI. Our prevalence may be underestimated and could mostly concern patients who are suffering from moderate to very severe forms. Mild forms of XLI are probably less bothersome and these patients may not consult a hospital 
or be members of patient's association or social network. This is in accordance with the small number of patients $(\mathrm{n}=73)$ diagnosed as XLI during the 10 past years in France using enzymatic blood test (personal data provided by the only French diagnosis centre).

\section{Conclusion}

This is the first French epidemiological study on ichthyosis. It focused on ichthyoses with significant impact on QOL, usually followed in hospital and for which medical, social or research progresses are needed. The obtained results constitute an essential basis for properly sizing the necessary health measures such as access to molecular diagnosis or design of clinical studies, especially in the domain of therapeutics in which there is a true lack.

\section{Competing interests}

The authors declare that they have no competing interest.

\section{Authors' contributions}

ID designed and coordinated the study, contributed to collecting data, performed the revision and the interpretation of all the clinical data and wrote the manuscript. CC and JD co-designed the study, performed the statistical analyses and co-wrote the manuscript. SP participated in the statistical analyses. SH, CC, AM, LR, PV, LM, SM and SB contributed to collecting data. KE contributed towards collecting data and revising the manuscript. JMH designed and co-coordinated the study, contributed to the acquisition and interpretation of data and co-wrote the manuscript. All authors read and approved the final manuscript.

\section{Acknowledgements}

We would like to thank the patients and the support group AlF and Guillaume Maneuf (Facebook: "Lichtyose: qu'est ce que c'est?") for their important contribution to this work. This study was funded by Eucérin laboratory, Paris, France and AIF.

\section{Author details}

${ }^{1}$ Reference Centre for Rare Skin Diseases, Dermatology Department, Larrey Hospital, CHU Toulouse, Toulouse, France. ${ }^{2}$ Institut de Mathématiques de Toulouse, Laboratoire de Statistique et Probabilités, CNRS (UMR 5219), Paul Sabatier University, Toulouse, France. ${ }^{3}$ Reference Centre for Rare Skin Diseases, Dermatology Department, CHU Bordeaux, Bordeaux, France. ${ }^{4}$ Reference Centre for epidermolysis bullosa, Dermatology Department, CHU Nice, Nice, France. ${ }^{5}$ Competence Centre for Rare Skin Diseases Dermatology Department, CHU Dijon, Dijon, France. ${ }^{6}$ Dermatology Department, $\mathrm{CHU}$ Angers, Angers, France. ${ }^{7}$ Dermatology Department, CHU Marseille, Marseille, France. ${ }^{8}$ Competence Centre for Rare Skin Diseases Dermatology

Department, CHU Nantes, Nantes, France.

Received: 26 July 2013 Accepted: 20 December 2013

Published: 6 January 2014

\section{References}

1. Oji $\mathrm{V}$, Traupe $\mathrm{H}$ : Ichthyosis: clinical manifestations and practical treatment options. Am J Clin Dermatol 2009, 10:351-364.

2. Oji V, Tadini G, Akiyama M, Blanchet Bardon C, Bodemer C, Bourrat E, Coudiere P, DiGiovanna JJ, Elias P, Fischer J, Fleckman P, Gina M, Harper J, Hashimoto T, Hausser I, Hennies HC, Hohl D, Hovnanian A, Ishida-Yamamoto A, Jacyk WK, Leachman S, Leigh I, Mazereeuw-Hautier J, Milstone L, Morice-Picard F, Paller AS, Richard G, Schmuth M, Shimizu H, Sprecher E, et al: Revised nomenclature and classification of inherited ichthyoses: results of the First Ichthyosis Consensus Conference in Sorèze 2009. J Am Acad Dermatol 2010, 63:607-641.

3. Gånemo A, Lindholm C, Lindberg M, Sjödén PO, Vahlquist A: Quality of life in adults with congenital ichthyosis. J Adv Nurs 2003, 44:412-419.
4. Gånemo A, Sjödén PO, Johansson E, Vahlquist A, Lindberg M: Health-related quality of life among patients with ichthyosis. Eur J Dermatol 2004, 14:61-66.

5. Kamalpour L, Gammon B, Chen KH, Veledar E, Pavlis M, Rice ZP, Chen SC: Resource utilization and quality of life associated with congenital ichthyoses. Pediatr Dermatol 2011, 28:512-518.

6. Mazereeuw - Hautier J, Dreyfus I, Barbarot S, Serrentino L, Bourdon - Lanoy E, Ezzedine K, Maza A, Aujoulat I, Le Rhun A: Factors influencing quality of life in patients with inherited ichthyosis : a qualitative study using focus groups. Br J Dermatol 2012, 166:646-648.

7. Dreyfus I, Bourrat E, Maruani A, Bessis D, Chiavérini C, Vabres P, Ezzedine K, Mazereeuw-Hautier J: Factors associated with impaired quality of life in adult patients suffering from inherited ichthyosis. Acta Derm Venereol. in press.

8. Fischer J: Autosomal recessive congenital ichthyosis. J Invest Dermatol 2009, 129:1319-1321.

9. Al-Zayir AA, Al-Amro Al-Alakloby OM: Primary hereditary ichthyoses in the eastern province of Saudi Arabia. Int J Dermatol 2004, 43:415-419.

10. Al-Zayir AA, Al-Amro Al-Alakloby OM: Clinico-epidemiological features of primary hereditary ichthyoses in the eastern province of Saudi Arabia. Int J Dermatol 2006, 45:257-264.

11. Al-Amro Al-Akloby OM, Al-Zayir AA: Clinico-epidemiological features of congenital nonbullous ichthyosiform erythroderma in the eastern province of Saudi Arabia. J Eur Acad Dermatol Venereol 2004, 18:659-664

12. Kharfi M, El Fekih N, Ammar D, Khaled A, Fazaa B, Ridha Kamoun M: Hereditary Ichthyosis in Tunisia: epidemiological of 60 cases. Tunis Med 2008, 86:983-986.

13. Rodríguez-Pazos L, Ginarte M, Fachal L, Toribio J, Carracedo A, Vega A: Analysis of TGM1, ALOX12B, ALOXE3, NIPAL4 and CYP4F22 in autosomal recessive congenital ichthyosis from Galicia (NW Spain): evidence of founder effects. Br J Dermatol 2011, 165:906-911.

14. Hernández-Martín A, Garcia-Doval I, Aranegui B, de Unamuno P, Rodríguez-Pazos L, González-Enseñat MA, Vicente A, Martín-Santiago A, Garcia-Bravo B, Feito M, Baselga E, Círia S, de Lucas R, Ginarte M, González-Sarmiento R, Torrelo A: Prevalence of autosomal recessive congenital ichthyosis: a population-based study using the capturerecapture method in Spain. J Am Acad Dermatol 2012, 67:240-244.

15. Milstone L, Miller K, Haberman M, Dickens J: Incidence of moderate to severe ichthyosis in the United States. Arch Dermatol 2012, 148:1080-1081.

16. Kurosawa M, Takagi A, Tamakoshi A, Kawamura T, Inaba Y, Yokoyama K, Kitajima Y, Aoyama Y, Iwatsuki K, Ikeda S: Epidemiology and clinical characteristics of bullous ichthyosisform erythroderma (keratinolytic ichthyosis) in Japan: results from a nationwide survey. J Am Acad Dermatol 2013, 68:278-283.

17. Le site santé du Ministère des Affaires sociales et de la Santé. http://www. sante.gouv.fr/IMG/pdf/Plan_national_maladies_rares_2011-2014.pdf.

18. International Working Group for Disease Monitoring and Forecasting (IWGDMF): Capture-recapture and multiple-record systems estimation I: history and theoretical development. Am J Epidemiol 1995, 142:1047-1058.

19. International Working Group for Disease Monitoring and Forecasting (IWGDMF): Capture-recapture and multiple-record systems estimation II: application in human diseases. Am J Epidemiol 1995, 142:1059-1068.

20. Chao A, Tsay PK, Lin SH, Shau WY, Chao DY: The applications of capturerecapture models to epidemiological data. Stat Med 2001, 20:3123-3157.

21. Hook EB, Albright SG, Cross PK: Use of Bernoulli census and log-linear methods for estimating the prevalence of spina bifida in livebirths and the completeness of vital record reports in New York State. Am J Epidemiol 1980, 112:750-758.

22. Hook EB, Regal RR: Recommendations for presentation and evaluation of capture-recapture estimates in epidemiology. J Clin Epidemio/ 1999, 52:917-926

23. Hook EB, Regal RR: On the need for a 16th and 17th recommendations for capture-recapture analysis. J Clin Epidemiol 2000, 53:1275-1277.

24. Dupuis JA, Schwarz CJ: A Bayesian approach to the multistate Jolly-Seber capture-recapture model. Biometrics 2007, 63:1015-1022.

25. Tilling K, Sterne J: Capture-recapture models including covariate effects. Am J Epidemiol 1999, 149:392-400.

26. Burnham KP, Anderson DR: Model selection and multimodel inference: a practical information-theoretic approach. New York: Springer; 2002.

27. Mann CJ: Cohort, cross sectional and case-control studies: research design II. Emerg Med J 2003, 20:54-60. 
28. Shtatland ES, Moore S, Barton MB: Why we need $R^{2}$ measure of fit (and not only one). In PROC LOGISTIC and PROC GENMOD. SUGI 2000 Proceeding. Cary, NC: SAS Institute, Inc; 2000:1338-1343. SUGI 2000 Proceeding.

29. Lykkesfeldt G, Nielsen MD, Lykkesfeldt AE: Placental steroid sulfatase deficiency: biochemical diagnosis and clinical review. Obstet Gynecol 1984, 64:49-54.

30. Wells RS, Kerr CB: Clinical features of autosomal dominant and sex-linked ichthyosis in an English population. Br Med J 1966, 1:947-950.

31. Ingordo V, D'Andria G, Gentile C, Decuzzi M, Mascia E, Naldi L: Frequency of X-linked ichthyosis in coastal southern Italy: a study on a representative sample of the male population. Dermatology 2003, 207:148-150.

32. Sakura N, Nichimura SI, Matsumoto T, Ohsaki M: Frequency of steroid sulfatase deficiency in Hiroshima. Acta Paediatr Jpn 1998, 40:63-64.

doi:10.1186/1750-1172-9-1

Cite this article as: Dreyfus et al:: Prevalence of inherited ichthyosis in France: a study using capture-recapture method. Orphanet Journal of Rare Diseases 2014 9:1.

\section{Submit your next manuscript to BioMed Central and take full advantage of:}

- Convenient online submission

- Thorough peer review

- No space constraints or color figure charges

- Immediate publication on acceptance

- Inclusion in PubMed, CAS, Scopus and Google Scholar

- Research which is freely available for redistribution 